\title{
HUBUNGAN PENGETAHUAN DAN PERILAKU IBU DENGAN KEJADIAN DIARE PADA BALITA DI WILAYAH KERJA PUSKESMAS KELAM TENGAH KABUPATEN KAUR
}

\section{THE RELATIONSHIP BETWEEN MOTHER'S KNOWLEDGE AND BEHAVIOR WITH THE CASE OF DIARRHEA IN TODDLERS IN THE WORK AREA OF THE KELAM TENGAH HEALTH CENTER IN KAUR REGENCY}

\author{
Oleh: \\ Agus Ramon ${ }^{1}$, Nopia Wati ${ }^{2}$, Eva Oktavidiati ${ }^{3}$, dan Nadia Wulandari ${ }^{3}$ \\ 1,2,3,4 Program Studi Kesehatan Masyarakat \\ Fakultas IImu Kesehatan Universitas Muhammadiyah Bengkulu \\ Agus@umb.ac.id
}

\begin{abstract}
Diarrhea is a condition in which a person defecates consistently with soft or liquid, even in form of water alone and the frequency is more frequent (usually three or more times) in one day. Diarrhea cases in Kaur Regency in last three years are still a health problem faced by The Kelam Tengah Public Health Center. This is related to the lack of knowledge and negative behavior of people in the working area of The Kelam Tengah Public Health Center. This study aims to determine correlation between knowledge and behavior of mothers with cases of diarrhea in children under five in the working area of Kelam Tengah Public Health Center, Kaur Regency. This research is a quantitative study with a cross sectional approach. This research was conducted in May 2020 in the work area of The Kelam Tengah Public Health Center. The study population consisted of 368 housewives with toddlers. The number of research samples were 92 mothers of children under five who were taken using random sampling technique. Data analysis was performed using the chi square test. The results of the study show that there was a significant correlation between mothers' knowledge $(P$ value $=0.000)$ and mothers' behavior $(P$ value $=0.000)$ with the incidence of diarrhea on children under five in the work area of The Kelam Tengah Public Health Center.

It is hoped that health workers who are in the working area of the Kelam Tengah community health center will provide counseling and health socialization related to the prevention of diarrhea in children.
\end{abstract}

Keywords: Diarrhea, Knowledge, Behavior.

\section{ABSTRAK}

Diare termasuk penyakit yang dapat menyebabkan penderitanya sering buang air besar, umumnya dengan tinja yang encer. Kajadian diare di Kabupaten Kaur dalam tiga tahun terakhir masih menjadi permasalahan kesehatan yang dihadapi Puskesmas Kelam Tengah, hal tersebut diduga berhubungan dengan kurangnya pengetahuan dan perilaku negatif masyarakat yang ada di wilayah kerja Puskesmas Kelam Tengah. Penelitian ini bertujuan untuk mengetahui hubungan pengetahuan dan perilaku ibu dengan kejadian diare pada balita di wilayah kerja puskesmas Kelam Tengah Kabupaten Kaur. Jenis penelitian ini adalah penelitian kuantitatif dengan pendekatan cross sectional. Penelitian ini dilakukan pada bulan Mei 2020 di wilayah kerja Puskesmas Kelam Tengah. Populasi penelitian terdiri dari ibu rumah tangga yang memiliki balita sebanyak 368 orang. Jumlah sampel penelitian sebanyak 92 ibu yang memiliki balita dipilih menggunakan teknik simple random sampling. Analisis data dengan uji chi square. Hasil penelitian menunjukan bahwa terdapat hubungan yang signifikan antara pengetahuan ibu $(P$ value $=0.000)$ dan perilaku ibu $(P$ value $=0.000)$ dengan kejadian diare pada balita di wilayah kerja Puskesmas Kelam Tengah. Diharapkan petugas kesehatan yang berada di wilayah kerja puskesmas Kelam Tengah untuk dapat melakukan penyuluhan dan promosi kesehatan terkait dengan pencegahan penyakit Diare pada anak.

Kata Kunci $\quad$ : Diare, Pengetahuan, Perilaku 


\section{PENDAHULUAN}

Penyakit diare masih menjadi permasalahan kesehatan global yang belum tertangani dengan baik. Hal ini terlihat dari data kasus diare pada balita mulai dari tahun 2015 hingga tahun 2017. Sebanyak 688 juta orang sakit dan hampir 500 ribu kematian di seluruh belahan dunia disebabkan diare. Sedangkan pada tahun 2017, sebanyak 1,6 miliar lebih anak-anak terkena diare, dan sebanyak 525 ribu anak balita meninggal setiap tahunnya (World Health Organization, 2017).

Pada data penyakit endemis potensial Kejadian Luar Biasa (KLB), penyakit diare sering menjadi penyumbang angka kematian di Indonesia. Sepuluh kali Kejadian Luar Biasa (KLB) Diare pernah terjadi pada tahun 2018 di delapan Provinsi, yakni Provinsi Papua, Nusa Tenggara Timur, Jawa Barat, Nusa Tenggara Barat, Maluku, Kalimantan Barat, Bali, dan Sulawesi Tengah dengan jumlah penderita sebanyak 756 orang dan yang meninggal dunia sebanyak 36 orang (CFR 4,76\%) (Ditjen P2P Kemenkes RI, 2019). Berdasarkan data Kejadian Luar Biasa Diare dari tahun 2010 hingga tahun 2018, menunjukan bahwa CFR pada saat Kejadian Luar Biasa masih cukup tinggi (>1\%) (Kemenkes, 2018).

Kasus Diare mengalami grafik naik turun dari tahun ke tahun di Indonesia, dan pada tahun 2014 terdapat 8.713.537 kasus Diare dengan kasus yang ditangani sebanyak 8.490 .976 atau $97,45 \%$, pada tahun 2015 kasus Diare secara nasional mengalami penurunan menjadi 5.405.235 kasus dengan kasus yang ditangani sebanyak 4 juta lebih $(74,3 \%)$, pada tahun 2016 bertambah lagi menjadi 6,8 juta kasus dengan kasus terlayani sekitar 2,5 juta $(36,9 \%)$, pada tahun 2017 kembali meningkat menjadi 7.077.299 kasus dengan kasus yang ditangani sekitar 4,2 juta atau 60,40\%, kemudian tahun 2018 terdapat sebanyak 7.157.483 kasus diare dengan kasus yang ditangani di fasilitas kesehatan sebanyak 4.504 .524 kasus atau 62,93\% (Profil Kesehatan Indonesia, 2014 - 2018).

Di Provinsi Bengkulu kasus diare dalam beberapa Tahun terakhir (2013, 2014, 2015, 2016, $2017,2018)$ terus mengalami kenaikan. Pada tahun 2013 terdapat 39.537 kasus dengan kasus yang ditangani sebanyak 18.268 kasus atau $46.2 \%$, pada tahun 2014 terdapat 39.479 kasus dengan kasus yang ditangani sebanyak 19.760 kasus atau $50.1 \%$, tahun 2015 terdapat 40.124 kasus dengan kasus yang ditangani sebanyak 32.849 kasus atau $82 \%$, tahun 2016 terdapat 50.622 kasus dengan kasus yang ditangani sebanyak 12.017 atau $23,7 \%$, pada tahun 2017 terdapat 52.225 kasus dengan kasus yang ditangani sebanyak 17.205 kasus atau $32,94 \%$, pada tahun 2018 terdapat 53.009 dengan kasus yang ditangani di fasilitas kesehatan sebanyak 21.093 atau 39,79\% (Dinas Kesehatan Provinsi Bengkulu, 2019).

Kabupaten Kaur merupakan pemekaran Kabupaten Bengkulu Selatan. Salah satu permasalahan kesehatan yang masih menjadi permasalahan serius yang belum teratasi di Kabupaten Kaur sampai saat ini adalah penyakit Diare. Penyakit diare merupakan penyakit yang dalam 5 tahun terakhir selalu masuk dalam 5 besar penyakit tertinggi di Kabupaten Kaur. Pada tahun 2019 terdapat 950 kasus diare, 437 kasus pada laki-laki dan 513 kasus pada perempuan. Kasus diare yang ditangani di fasilitas kesehatan masih tergolong sangat rendah yaitu hanya 276 kasus atau $29,07 \%$ dari total kasus yang ditemukan di 15 kecamatan (Dinas Kesehatan Kabupaten Kaur, 2020).

Pada tahun 2019 terdapat 281 kasus diare, 113 kasus pada laki-laki dan sisanya 168 kasus pada perempuan. Dari 281 kasus diare pada tahun 2019 di wilayah kerja Puskesmas Kelam Tengah, 143 kasus atau $53 \%$ nya terjadi pada kelompok usia balita. Jumlah Balita yang ada di wilyah kerja Puskesmas Kelam Tengah pada tahun 2020 adalah sebanyak 368 balita, yang terdiri dari 154 balita laki-laki dan 214 balita perempuan (Puskesmas Kelam Tengah, 2020).

Hasil penelitian Yarmaliza (2017) menunjukan pengetahuan sang ibu dan perilaku ibu saling berhubungan erat dengan kejadian diare pada balita di wilaya kerja Puskesmas Kecamatan Meureubo, Aceh Barat.

Berdasarkan pengumpulan data awal yang dilakukan penulis pada tanggal 06 Nopember 2019 dengan melakukan wawancara terhadap 5 orang Ibu balita yang memiliki riawayat diare di wilayah kerja Puskesmas Kelam Tengah, menunjukan bahwa 4 orang ibu memiliki pengetahuan kurang terhadap penyakit diare dimana lbu balita tidak mengetahui frekuensi buang air besar yang bisa dikatakan diare, tidak mengetahui penyebab penyakit diare, tidak mengetahui bagaimana penyakit diare menyebar, dan beberapa ibu balita 
tidak mengetahui cara pengobatan serta pencegahan penyakit diare. Selain pengetahuan, terdapat 3 orang ibu balita dengan perilaku kurang baik dimana beberapa ibu balita tidak memberikan ASI eksklusif (0-6 bulan) kepada balita, beberapa ibu memiliki kebiasaan tidak mencuci dengan air mengalir bahan makanan yang akan dimasak, tidak membersihkan tangan ketika akan mempersiapkan makan anak, beberapa ibu tidak menyimpan makanan pada tempat yang tertutup rapat, beberapa ibu balita tidak membuang tinja balita di jamban (survei awal, 2019).

\section{METODE PENELITIAN}

Jenis penelitian yang digunakan pada penelitian ini adalah jenis penelitian survey analitik dengan metode kuantitatif. Populasi dalam penelitian ini adalah seluruh lbu Rumah Tangga (IRT) yang memiliki balita di wilayah kerja
Puskesmas Kelam Tengah Kabupaten Kaur yaitu sebanyak 368 orang. Dalam penelitian ini teknik pengambilan sampel menggunakan teknik simple random sampling, sampel minimum sebanyak 92 orang. Data primer dan data sekunder adalah teknik yang digunakan dalam pengumpulan data. Teknik analisa data menggunakan analisis univariat dan analisis bivariat.

\section{HASIL PENELITIAN \\ Analisis Univariat}

Analisis univariat bertujuan untuk mendeskripsikan atau memberikan gambaran distribusi frekuensi responden berdasarkan variabel penelitian, baik variabel independen maupun variabel dependen. Dapat dilihat pada Tabel berikut ini:

Deskripsi responden penelitian berdasarkan usia dapat dilihat pada Tabel berikut ini:

Tabel 1

Deskripsi Responden Berdasarkan Usia

\begin{tabular}{cccccc}
\hline \multicolumn{7}{c}{ Descriptive Statistics } \\
\hline Usia & $\mathrm{N}$ & Minimum & Maximum & Mean & Std. Deviation \\
\hline & 92 & 21 & 49 & 31.13 & 6.365
\end{tabular}

Sumber: Data primer yang diolah, 2020

Pada Tabel terlihat bahwa responden penelitian tertua berusia 49 tahun dan responden termuda berusia 21 tahun. Rata-rata usia responden penelitian adalah 31,13 tahun.
Berdasarkan tingkat pendidikan dapat dilihat pada Tabel berikut ini:

Tabel 2

Distribusi Responden Berdasarkan Pendidikan

\begin{tabular}{|c|c|c|c|c|}
\hline No & Variabel Penelitian & Kategori & $\begin{array}{c}\text { Frekuensi } \\
\text { (n) }\end{array}$ & $\begin{array}{c}\text { Persentase } \\
(\%)\end{array}$ \\
\hline \multirow[t]{5}{*}{1} & Pendidikan & SD & 10 & 10.9 \\
\hline & & SMP & 17 & 18.5 \\
\hline & & SMA & 27 & 29.3 \\
\hline & & D3/S1 & 38 & 41.3 \\
\hline & Total & & 92 & 100 \\
\hline
\end{tabular}

Sumber: Data primer yang diolah, 2020

Dari Tabel di atas dapat diketahui bahwa dari 92 orang responden, responden dengan pendidikan D3/S1 sebanyak 38 orang $(41,3 \%)$, responden dengan pendidikan SMA sebanyak 27 orang $(29,3 \%)$, responden dengan pendidikan SMP sebanyak 17 orang $(18,5 \%)$ dan responden dengan pendidikan SD sebanyak 10 orang (10.9\%).

Deskripsi responden penelitian berdasarkan kejadian diare dapat dilihat pada Tabel berikut ini:

Tabel 3 


\section{Deskripsi Responden Penelitian Berdasarkan Kejadian Diare}

\begin{tabular}{|c|c|c|c|c|}
\hline No & Variabel Penelitian & Kategori & Frekuensi (n) & Persentase (\%) \\
\hline & \multirow{2}{*}{ Kejadian Diare } & Diare & 36 & 39.1 \\
\hline & & Tidak Diare & 56 & 60.9 \\
\hline & Total & & 92 & 100 \\
\hline
\end{tabular}

Sumber: Data primer yang diolah, 2020

Tabel menjelaskan bahwa dari 92 orang responden, yang terkena diare sebanyak 36 orang $(39,1 \%)$ dan responden yang tidak diare sebanyak 56 orang $(60,9 \%)$.
Distribusi responden penelitian berdasarkan pengetahuan terlihat pada Tabel berikut:

\section{Tabel 4}

Distribusi Responden Berdasarkan Pengetahuan

\begin{tabular}{ccccc}
\hline No & Variabel Penelitian & Kategori & Frekuensi (n) & Persentase (\%) \\
\hline 1 & Pengetahuan & Kurang & 43 & 46.7 \\
& & Cukup & 19 & 20.7 \\
& & Baik & 30 & 32.6 \\
\hline \multicolumn{1}{c}{ Total } & & 92 & 100
\end{tabular}

Sumber: Data primer yang diolah, 2020

Dari Tabel di atas dapat diketahui bahwa dari 92 orang responden, 43 orang $(46,7 \%)$ memiliki pengetahuan yang kurang, 30 orang $(32,6 \%)$ memiliki pengetahuan yang baik, dan 19 orang $(20,7 \%)$ memiliki pengetahuan yang cukup.

Deskripsi responden penelitian berdasarkan Perilaku dapat dilihat pada Tabel berikut ini:

Tabel 5

Deskripsi Responden Penelitian Berdasarkan Perilaku

\begin{tabular}{ccccc}
\hline No & \multirow{2}{*}{ Variabel Penelitian } & Kategori & $\begin{array}{c}\text { Frekuensi } \\
(\mathrm{n})\end{array}$ & $\begin{array}{c}\text { Persentase } \\
(\%)\end{array}$ \\
\hline 1 & Perilaku & Negatif & 47 & 51.1 \\
& & Positif & 45 & 48.9 \\
\hline \multicolumn{2}{r}{} & & 92 & 100 \\
\hline
\end{tabular}

Sumber: Data primer yang diolah, 2020

Berdasarkan Tabel di atas dari 92 orang responden, sebanyak 47 orang $(51,1 \%)$ dengan perilaku negatif dan responden dengan perilaku positif sebanyak 45 orang $(48,9 \%)$.

\section{Analisis Bivariat}

Hasil analisis bivariat masing-masing variabel dengan bantuan aplikasi perangkat lunak SPSS versi 21.

Hubungan antara variabel pengetahuan dengan kejadian diare dapat dilihat pada Tabel berikut ini:

Tabel 6 
Hubungan Pengetahuan Dengan Kejadian Diare

\begin{tabular}{cccccccc}
\hline \multirow{2}{*}{ Pengetahuan } & \multicolumn{4}{c}{ Kejadian Diare } & \multicolumn{2}{c}{ Total } & P \\
& \multicolumn{2}{c}{ Diare } & \multicolumn{2}{c}{ Tidak Diare } & \multicolumn{2}{c}{} & Value \\
& $\mathbf{N}$ & $\%$ & $\mathbf{N}$ & $\%$ & $\mathbf{N}$ & $\%$ & \\
\hline Kurang & 30 & 69.8 & 13 & 30.2 & 43 & 46.7 & \\
Cukup & 3 & 15.8 & 16 & 84.2 & 19 & 20.7 & 0.000 \\
Baik & 3 & 10 & 27 & 90 & 30 & 32.6 & \\
\hline Total & $\mathbf{3 6}$ & & $\mathbf{5 6}$ & & $\mathbf{9 2}$ & $\mathbf{1 0 0}$ & \\
\hline
\end{tabular}

Sumber: Data primer yang diolah, 2020

Pada Tabel 6 hasil pada tabel antara pengetahuan dengan kejadian diare diketahui, dari 43 responden dengan pengetahuan kurang, 30 responden $(69,8 \%)$ diare dan 13 responden $(30,2 \%)$ tidak diare. Dari 19 responden dengan pengetahuan cukup, 3 responden $(15,8 \%)$ diare dan 16 responden (84.2\%) tidak diare. Sedangkan dari 30 orang responden dengan pengetahuan baik, 3 orang responden (10\%) diare dan 27 orang $(90 \%)$ tidak diare.

Hasil analisis bivariat dengan digunakannya uji Chi-Square mendapatkan hasil yaitu nilai $P$ value pada Pearson Chi-Square sebesar 0.000 kurang dari nilai alpha yaitu 0.05 , sehingga kesimpulannya adanya hubunga signifikan antara pengetahuan dengan kejadian diare pada balita di wilayah Puskesmas Kelam Tengah.

Tabulasi silang antara variabel perilaku dengan kejadian diare di atas dapat terlihat, dari 47 responden dengan perilaku negatif, 31 responden $(66 \%)$ diare dan 16 orang responden (34\%) tidak diare. Sedangkan dari 45 responden dengan perilaku positif, 5 orang responden $(11,1 \%)$ responden diare dan 40 orang $(88,9 \%)$ responden Diare.

Hasil analisis bivariat dengan digunakannya uji Chi-Square di dapatkan nilai $\mathrm{P}$ value pada Continuity Corecction sebesar 0,000 kurang dari nilai alpha yaitu 0.05 , sehingga kesimpulannya adalah adanya hubungan signifikan antara perilaku dengan kejadian diare pada balita di wilayah Puskesmas Kelam Tengah.

\section{PEMBAHASAN}

\section{Hubungan Pengetahuan Dengan Kejadian Diare Pada Balita}

Hasil tabulasi persilangan antara pengetahuan dengan kejadian diare diketahui, dari 43 responden dengan pengetahuan kurang, 30 responden $(69,8 \%)$ diare dan 13 responden $(30,2 \%)$ tidak diare. Dari 19 responden dengan pengetahuan cukup, 3 responden $(15,8 \%)$ diare dan 16 responden $(84.2 \%)$ tidak diare. Sedangkan dari 30 orang responden dengan pengetahuan baik, 3 orang responden (10\%) diare dan 27 orang $(90 \%)$ tidak diare.

Hasil analisis data menggunakan uji chisquare, memberikan hasil dimana adanya hubungan signifikan antara pengetahuan ibu dengan kejadian diare pada balita di wilayah kerja Puskesmas Kelam Tengah Kabupaten Kaur. Hubungan signifikan ini dilihat secara statistik dengan nilai $p$-value 0,000 kurang dari nilai alpha 0,05 . Hasil analisis menunjukan bahwa mayoritas responden penelitian memiliki pengetahuan kurang mengenai penyakit diare, hal tersebut berhubungan dengan pendidikan responden penelitian dimana sebagian besar responden memiliki pendidikan SMA ke bawah. Salah satu faktor utama yang dapat mempengaruhi pengetahuan ibu balita adalah pendidikan, dimana pada akhirnya akan membentuk perilaku ibu dalam mencegah dan penatalaksanaan penyakit diare pada balita.

\section{Hubungan Perilaku Ibu Dengan Kejadian Diare Pada Balita}

Hasil persilangan antara variabel perilaku dengan kejadian diare di atas dapat diketahui bahwa, dari 47 responden dengan perilaku negatif, 31 responden $(66 \%)$ diare dan 16 orang responden $(34 \%)$ tidak diare. Sedangkan dari 45 responden 
dengan perilaku positif, 5 orang responden $(11,1 \%)$ responden diare dan 40 orang $(88,9 \%)$ responden Diare.

Hasil analisis menggunakan uji Chi-Square di dapatkan nilai $P$ value pada Continuity Corecction sebesar 0,000 kurang dari nilai alpha yaitu 0.05 , sehingga disimpulkan bahwa adanya hubungan signifikan antara perilaku dengan kejadian diare pada balita di wilayah Puskesmas Kelam Tengah. Hasil analisis menunjukan bahwa mayoritas responden penelitian memiliki perilaku negatif, hal tersebut berhubungan dengan kondisi pendidikan dan pengetahuan responden penelitian dimana sebagian besar responden penelitian memiliki pendidikan SMA ke bawah dan terbanyak responden memiliki pengetahuan kurang terhadap penyakit diare. Pendidikan dan pengetahuan ibu merupakan faktor yang seringkali menjadi penentu bagaimana ibu balita berperilaku dalam pencegahan dan penatalaksanaan penyakit diare yang pada akhirnya berpengaruh terhadap kejadian diare pada balita.

\section{KESIMPULAN}

Dari 92 orang responden, responden diare sebanyak 36 orang $(39,1 \%)$ dan responden yang tidak diare berjumlah 56 orang $(60,9 \%)$.

Dari 92 orang responden, responden yang pengetahuannya kurang berjumlah 43 orang $(46,7 \%)$, responden yang pengetahuannya cukup berjumlah 19 orang $(20,7 \%)$, dan responden yang pengetahuannya baik berjumlah 30 orang $(32,6 \%)$.

Dari 92 orang responden, responden dengan perilaku negatif berjumlah 47 orang $(51,1 \%)$ dan perilaku positif berjumlah 45 orang $(48,9 \%)$.

Adanya hubungan signifikan antara pengetahuan ibu dengan kejadian diare pada balita di wilayah Puskesmas Kelam Tengah nilai $P$ value yaitu 0.000 kurang dari nilai alpha yaitu 0.05 .

Adanya hubungan signifikan antara perilaku ibu dengan kejadian diare pada balita di wilayah Puskesmas Kelam Tengah dengan nilai $P$ value yaitu 0.000 kurang dari nilai alpha 0.05 .
Disarankan kepada pihak Puskesmas Kelam Tengah untuk dapat menggalakan penyuluhan kesehatan untuk meningkatkan pengetahuan masyarakat terkait dengan faktor risiko kejadian diare dan perilaku pencegahan kejadian diare pada balita.

\section{DAFTAR PUSTAKA}

Arikunto, Suharsimi. 2013. Prosedur Penelitian Suatu Pendekatan Praktik. Jakarta: Rineka Cipta.

Azmi, dkk. 2018. Hubungan Sanitasi Lingkungan Dengan Kejadian Diare Pada Anakbalita Di Wilayah Kerja Puskesmasbambaira Kabupaten Pasangkayu. Jurnal Fakultas Kesehatan Masyarakatuniversitas Muhammadiyah Palu.

Azwar, Saifuddin. 2008. Reliabilitas dan Validitas. Yogyakarta : Pustaka Pelajar.

Departemen Kesehatan Republik Indonesia. 2005. Buku Pedoman Penatalaksanaan Program P2 Diare. Jakarta: Ditjen PPM dan PL.

Departemen Kesehatan Republik Indonesia. 2011. Buku Saku Petugas Kesehatan Lintas Diare. Jakarta: Ditjen PPM dan PL.

Dinas Kesehatan Kabupaten Kaur. 2019. Profil Kesehatan Kabupaten Kaur Tahun 2019. Kaur: Dinas Kesehatan Kabupaten Kaur.

Dinas Kesehatan Kabupaten Kaur. 2020. 10 Penyakit Dengan Kasus Tertinggi Di Kabupaten Kaur. Kaur: Dinas Kesehatan Kabupaten Kaur.

Dinas Kesehatan Provinsi Bengkulu. 2013. Profil Kesehatan Provinsi Bengkulu. Bengkulu: Dinas Kesehatan Provinsi Bengkulu.

Dinas Kesehatan Provinsi Bengkulu. 2018. Profil Kesehatan Provinsi Bengkulu. Bengkulu: Dinas Kesehatan Provinsi Bengkulu.

Dinas Kesehatan Provinsi Bengkulu. 2019. Profil Kesehatan Provinsi Bengkulu. Bengkulu: Dinas Kesehatan Provinsi Bengkulu.

Direktur Jendral Pencegahan Dan Pengendalian Penyakit. 2018. Buku Saku Petugas Kesehatan Lintas Diare Lima Langkah Tuntaskan Diare. Jakarta: Kementerian Kesehatan Republik Indonesia.

Direktur Jendral Pencegahan Dan Pengendalian Penyakit. 2019. Rekapitulasi Kejadian Luar Biasa Diare Tahun 2018. Jakarta:

\section{SARAN}


Kementerian Kesehatan Republik Indonesia.

Kementerian Kesehatan. 2018. Profil Kesehatan Indonesia Tahun 2017. Jakarta: Kementerian Kesehatan Republik Indonesia.

Kementerian Kesehatan. 2019. Profil Kesehatan Indonesia Tahun 2018. Jakarta: Kementerian Kesehatan Republik Indonesia.

Khasanah, Uswatun \& Galuh Kartika Sari. 2016. Hubungan Tingkat Pengetahuan Ibu Tentang Diare Dengan Perilaku Pencegahan Diare Pada Balita. Jurnal Kesehatan "Samodra IImu" Vol. 07 No. 02.

Laksmi ,N.P.A., IGA Trisna Windiani., \& I Nyoman Budi Hartawan. 2013. Hubungan Perilaku Ibu Terhadap Kejadian Diare Pada Balita Di Wilayah Kerja Puskesmas Sukawati I Periode Bulan November Tahun 2013. Jurnal Kesehatan Universitas Udayana.

Lidiawati, Meli. 2016. Hubungan Sanitasi Lingkungan Dengan Angka Kejadian Diare Pada Balita Di Wilayah Kerja Puskesmas Meuraxa Tahun 2016. Serambi Saintia, Vol. IV, No. 2, Oktober 2016

Maulana, Luthfi Hidayat. 2017. Faktor-Faktor Yang Berhubungan Dengan Kejadian Diare Pada Balita Di Wilayah Puskesmas Winduaji Kabupaten Brebes Tahun 2017. Jurnal
Kesehatan Fakultas Sains dan Teknologi, Universitas Peradaban.

Ngastiyah. 2005. Perawatan Anak Sakit. Jakarta: EGC

Notoatmodjo, Soekidjo. 2011. Promosi Kesehatan dan Perilaku Kesehatan. Jakarta. Rineka Cipta.

Notoatmodjo, Soekidjo. 2012. Metodologi Penelitian Kuantitaf. Jakarta: Rineka Cipta.

Prita, Nimas., Agus Fitriangga., \& Diana Natalia. 2014. Hubungan Antara Perilaku Ibu Dan Kejadian Diare Pada Bayi Di Wilayah Kerja Puskesmas Siantan Hilir. Jurnal Kesehatan Universitas Tanjungpura.

Puskesmas Kelam Tengah. 2020. Profil Kesehatan Puskesmas Kelam Tengah. Kaur. Puskesmas Kelam Tengah.

Rane, Silvia., Yusri Dianne Jurnalis., \& Djusmaini Ismail. Hubungan Tingkat Pengetahuan Ibu Tentang Diare Dengan Kejadian Diare Akut pada Balita di Kelurahan Lubuk Buaya Wilayah Kerja Puskesmas Lubuk Buaya Padang. Jurnal Kesehatan Andalas, 2017 Volume 6, No 2 .

Simadibrata, MK. 2006. Pendekatan Diagnostik Diare Kronik. Di dalam : Sudoyo Aru w et al, editor. Buku Ajar IImu Penyakit Dalam. Jilid I Edisi IV. Jakarta: Pusat Penerbitan Depertemen IImu Penyakit Dalam FK UI. 